\title{
ChemComm
}

Check for updates

Cite this: Chem. Commun., 2022, 58,4468

Received 2nd December 2021, Accepted 1st March 2022

DOI: $10.1039 / \mathrm{d} 1 \mathrm{cc} 06790 \mathrm{~g}$

rsc.li/chemcomm

\section{Imaging deposition-dependent supramolecular chiral organisation $\dagger$}

\author{
C. Elizabeth Killalea, (D) ${ }^{\text {ab }}$ Mario Samperi, (D) $\ddagger^{\mathrm{a}}$ Giuliano Siligardi (D) ${ }^{\mathrm{c}}$ and \\ David B. Amabilino (D) *ad
}

\begin{abstract}
Thin films of a chiral diketopyrrolopyrrole derivative were imaged with spatially-defined Mueller Matrix Polarimetry, focussing on the Circular Dichroism signal, giving unique insight into the impact that deposition techniques and thermal annealing can have on chiral supramolecular structures in the solid state, where homogeneity was observed for spun-coated films while drop-coating afforded chiroptical diversity in the material, a feature invisible to absorption spectroscopy or optical microscopy.
\end{abstract}

The morphology of thin films influences greatly the efficiency of organic photovoltaic (OPVs) and other organic devices. ${ }^{1}$ Control of this morphology can be achieved by: (i) changing the composition and constitution of materials that self-assemble, (ii) the method of deposition, ${ }^{2}$ and (iii) post-deposition annealing processes. OPVs often incorporate branched moieties to influence aggregation, ${ }^{3}$ and chirality does, in certain cases, affect device performance through morphological variation. ${ }^{4-6}$ In basic research, spin coating is perhaps the most commonly used method for deposition as a result of its ease of use and reproducibility for uniform films, ${ }^{7}$ where morphology can be strongly affected by solvent ${ }^{8}$ and spin speed. ${ }^{9}$ Post-deposition thermal- or solvent-annealing can improve film morphology and therefore the efficiency of devices. ${ }^{10}$

However, the exact microstructure across these thin films is often unknown because determining and imaging structure is hugely challenging. Diffraction techniques cannot precisely

\footnotetext{
${ }^{a}$ School of Chemistry and GSK Carbon Neutral Laboratories for Sustainable Chemistry, University of Nottingham, Triumph Road, Nottingham, NG7 2TU, UK

${ }^{b}$ School of Physics and Astronomy, The University of Nottingham, University Park, Nottingham, NG7 2RD, UK

${ }^{c}$ Diamond Light Source, Harwell Science and Innovation Campus, Didcot, Oxfordshire OX11 ODE, UK

${ }^{d}$ Institut de Ciència de Materials de Barcelona (ICMAB-CSIC), Campus Universitari de Cerdanyola, 08193 Spain

$\dagger$ Electronic supplementary information (ESI) available: Detailed synthetic and preparative procedures, supporting analytical data. See DOI: 10.1039/d1cc06790g \# Present address: Istituto di Tecnologie Avanzate per l'Energia "Nicola Giordano" - CNR-ITAE, Messina, Italy.
}

reveal the local packing in films ${ }^{11}$ because they are amorphous or only partly crystalline, lacking the long-range order required for many diffraction methods. Amorphous regions are poorly understood. Electron microscopy ${ }^{12}$ and energy dispersive X-ray (EDX) analysis have also been employed but because organic films typically only consist of light elements, there is rarely enough contrast to be able to distinguish domains. Atomic Force Microscopy (AFM) is often used to screen these films down to nanometric precision but is surface-specific; the interior of the film remains unprobed. ${ }^{13}$

Circular Dichroism (CD) spectroscopy is very sensitive to organic group's relative orientations. ${ }^{14,15}$ Unlike diffraction techniques, CD does not require long-range order and so it is particularly suited to observing short-range chiral arrangements in organic films, ${ }^{16-20}$ where film thickness can cause significant changes in the optical activity. ${ }^{21}$ However, CD spectroscopy generally lacks spatial resolution to reveal intricacies. A commercial instrument's spatial resolution is around $0.5 \mathrm{~cm}^{2}$, so averaged signals are observed. The highly collimated light at CD beamline B23 at Diamond Light Source, UK, allows spatial resolution down to $50 \mu \mathrm{m}$ and mapping of films. ${ }^{22-25}$ An $X-Y$ motorized and temperature-controlled stage (Linkam MDS600) allows $\mathrm{CD}$ imaging $(\mathrm{CD} i)$ measuring spatially resolved spectra in the 190-650 $\mathrm{nm}$ wavelength region at the highest spatial resolution of $50 \mu \mathrm{m}$ also as a function of temperature to study the effects of annealing on the supramolecular structure in situ.

Derivatives of 1,4-diketopyrrolo[3,4-c]pyrrole (DPP) are interesting as active layer components of OPVs,${ }^{26-28}$ and their selfassembly can give films with excellent properties. ${ }^{29} \mathrm{OPV}$ s made from chiral DPPs can have efficiency modulated by symmetry, and CD spectra of films of these materials show large differences in the supramolecular order, ${ }^{30}$ albeit at a large scale lacking spatial resolution. Here, we will show how the mapping and sensitivity of CD to supramolecular conformation can reveal differences and changes in the organisation of a chiral organic dye (1, Fig. 1) in films through variation of the processing parameters used in the film preparations. 


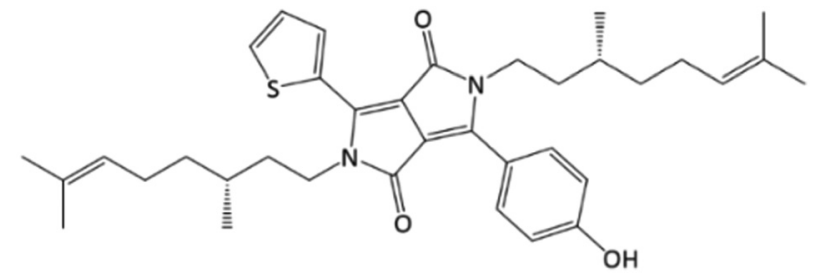

Fig. 1 Chemical structure of 1.

DPP 1 was synthesised in several steps (Scheme S1, ESI $\dagger$ ) using similar procedures described for related achiral materials. ${ }^{31-33}$ The CD spectra of $\mathbf{1}$ in toluene $(3.41 \mathrm{mM})$ correspond to a fully dissolved molecule (Fig. S1, ESI $\dagger$ ). In cyclohexane, temperature and concentration dependent $\mathrm{CD}$ indicates aggregation resulting in a red shifted negative $\mathrm{CD}$ band. A $0.34 \mathrm{mM}$ solution of 1 showed little effect on the CD upon cooling (Fig. S2, ESI $\dagger$ ), despite an increased in absorbance intensity. At $0.46 \mathrm{mM}$, on cooling from 60 to $5{ }^{\circ} \mathrm{C}$ a substantial and reproducible hypochromic effect occurs, consistent with J-type aggregate accompanied by redshifted CD bands (Fig. S3 and S4, ESI $\dagger$ ).

Films of 1 from chloroform were prepared with two methods: spin- and drop-coating (Fig. S5, ESI $\dagger$ ). AFM of both films showed that the surface topography differed significantly. The spin-coated were expectedly the much more homogeneous and uniform films, all areas scanned had similar features (Fig. S5 and S6 (ESI $\dagger$ ), average roughness $4.6 \pm 0.2 \mathrm{~nm}$ ). The drop-coated films had a roughness over $20 \mathrm{~nm}$ (Fig. S7 and S8, ESI $\dagger$ ). Comparison of the films at $1 \times 1 \mu \mathrm{m}$ scale (Fig. S5, ESI $\dagger$ ) shows the continuity of the spin-coated film, without well-defined domain boundaries, whilst the drop-coated samples apparently contained small crystallites.

The supramolecular structure within the bulk was studied using the noted beamline with both CD imaging (CDi) ${ }^{22-24}$ and Mueller Matrix Polarimetry (MMP) facilities. ${ }^{25}$ MMP measurements allow disambiguation of the various polarization properties that can affect CD. Here, CD, circular birefringence (CB), linear dichroism (LD), linear birefringence (LB) and absorption were performed simultaneously with MMP for both drop- and spin-coated films of 1 prepared from chloroform solution. For the purposes of this study, only the CD (that have negative maxima at approximately 284, 360 and a broader positive band with maximum at about $408 \mathrm{~nm}$ ) and absorption (maxima at around 280, 360 and 510) spectra are discussed and analysed. The $\mathrm{CD}$ of the films is quite different to that of solution aggregates, a common situation for hierarchical aggregation.

To probe annealing effects initially, twenty-five absorption and CD spectra in the 200-650 $\mathrm{nm}$ spectral region were recorded by raster scanning a $5 \times 5$ grid array (Fig. S9, ESI $\dagger$ ) with step size of $400 \mu \mathrm{m}$ using the B23 focused beam light of about $50 \times 30 \mu \mathrm{m}$ cross section. The spectra of thin films of 1 were measured at 20,70, 120 and $170{ }^{\circ} \mathrm{C}$ (below the melting point of $1,181-184{ }^{\circ} \mathrm{C}$ ) to assess the annealing effect to the sample's supramolecular structure. For both spin-coated (Fig. S10 and S11, ESI $\dagger$ ) and drop coated films (Fig. S12 and S13, ESI $\dagger$ ), the greatest effect of increasing optical activity with temperature was observed at $120{ }^{\circ} \mathrm{C}$ (Fig. S14 and S15, ESI $\dagger$ ), which was chosen for the subsequent imaging measurements as the optimum annealing temperature.

To ensure the same area of the film was studied before and after thermal annealing with the vertical chamber for CDi, the MMP tower, and an optical microscope, the film was masked leaving a circular area exposed. The wider area maps show a circular area inscribed in a dark, optically inactive square (Fig. S16, ESI $\dagger$ ). The CD and absorption maps from MMP scan at single wavelength (where signal to noise is highest) of thin films of 1 from drop- and spin-coated deposition methods were apparently quite different (Fig. S16, ESI $\dagger$ ), although controls are necessary. They were consistent with the AFM observations that the spin-coated film was much more uniform than that of the drop-coated film (Fig. S5-S8, ESI $\dagger$ ).

A more detailed spectroscopic study conducted on a 9 by 9 grid of the drop-coated film at $400 \mu \mathrm{m}$ steps (81 spectra) in the 200-600 $\mathrm{nm}$ region revealed that many of the investigated 81 spots had absorption spectra exceeding the optimum intensity magnitude range between 0.4 and 1.6 (Fig. S17 and S18, ESI $\dagger$ ). Outside that range, some the CD spectra showed a very intense positive band at about $400 \mathrm{~nm}$ that was negative in other areas, or very small in others. Certain CD spectra (Fig. S18, $\mathbf{5 E}^{\prime}$ and $\mathbf{5} \mathbf{F}^{\prime}$, ESI $\dagger$ ) though resembling others (such as $\mathbf{5 G}^{\prime}$ ), showed excessive absorption intensity, and may contain spectral distortions, giving artefacts in CD spectra. From these spectra, the absorption and $\mathrm{CD}$ values at $284 \mathrm{~nm}$ of the 81 spot coordinates were plotted as 2D maps (Fig. S17, ESI $\dagger$ ). The results show that relying only on the values at single wavelength could lead to misinterpretation of the optical activity of the material. Once the area is scanned with full spectra with a course grid area, for example, $4 \times 4$ or $5 \times 5$ at 0.5 to $1 \mathrm{~mm}$ steps, a single wavelength map can be re-scanned at much higher spatial resolution of 50 or $100 \mu \mathrm{m}$. Examples for drop- and spincoated films are shown in Fig. 2 and 3, respectively.

The same type of MMP measurements (the full maps are given in Fig. S20 and S21 (ESI $\dagger$ ) for the drop-coated film) were conducted with the spin-coated film of 1 . The absorption and CD 2D maps at single wavelength $(284 \mathrm{~nm})$ confirmed by the full spectra in the 200-600 $\mathrm{nm}$ region that a much more uniform and homogeneous spin coated thin film (Fig. S22, ESI $\dagger$ ) had been prepared compared to that of the drop coated film. Only 7 spots out of 81 showed much higher absorption (Fig. S22A and C, white labels, ESI $\dagger$ ) than the rest of the spots, which were clustered with similar optimal absorption spectra (Fig. S22D, ESI $\dagger$ ) and located at the four corners (Fig. S22A, $\mathrm{ESI} \dagger)$.

The comparison of the spectral data for spin- and dropcoated films is better illustrated in terms of $g$-factor (or dissymmetry factor $),{ }^{34}$ the ratio between the CD in $\Delta A\left[\Delta A=\left(A_{\mathrm{L}}-A_{\mathrm{R}}\right)\right.$, where $A_{\mathrm{L}}$ and $A_{\mathrm{R}}$ are the absorption of left and right circularly polarized light] over the absorption $A\left[A=\left\{\left(A_{\mathrm{L}}+A_{\mathrm{R}}\right) / 2\right\}\right]$. It is concentration independent, so any spectral difference in $g$-factor terms represent conformational and supramolecular differences of 1 in the films. The $g$-factor of the 74 spots of the 2D map of the spin-coated thin film of $\mathbf{1}$ are tightly clustered and superimposed to a large degree, confirming the film's uniform and 

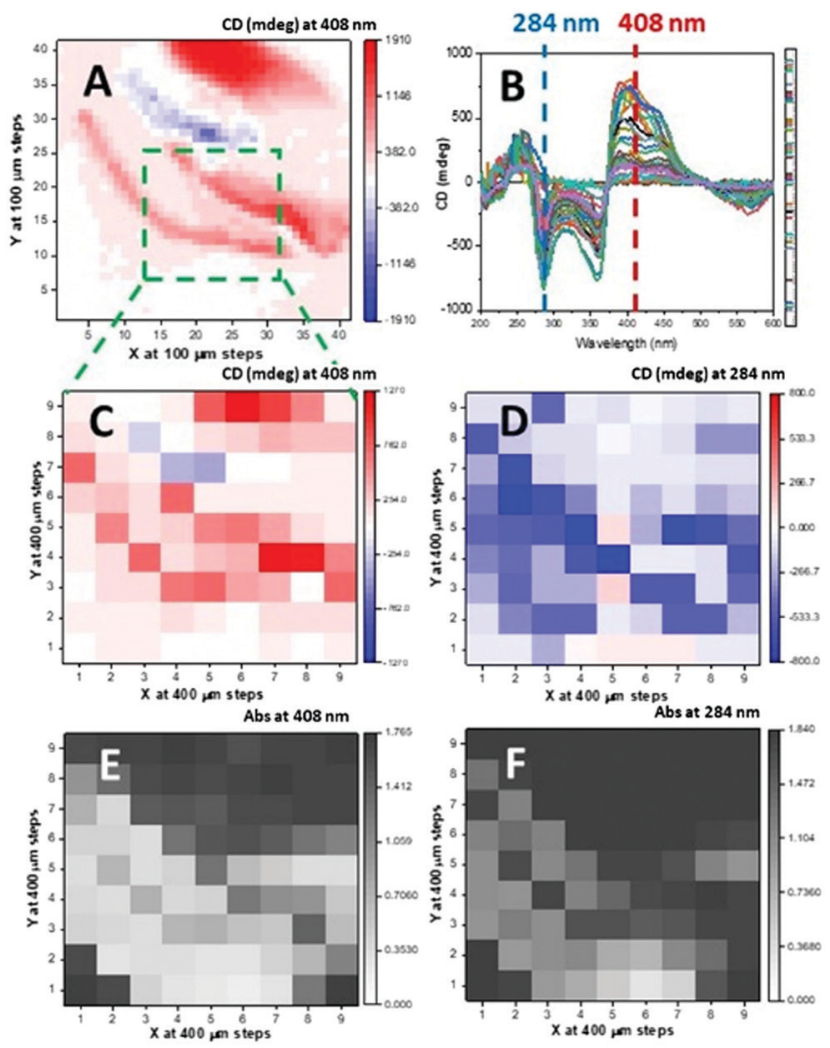

Fig. 2 (A) $2 \mathrm{D}$ map of $4 \times 4 \mathrm{~mm}$ area of $41 \times 41$ grid at $100 \mu \mathrm{m}$ steps scanned at $408 \mathrm{~nm}$ of drop-coated film. From this initial 2D map a smaller area of $3.2 \times 3.2 \mathrm{~mm}$ (dashed green line) was selected having reasonable transmission and 81 MMP CD spectra were scanned of the $9 \times 9$ grid at $400 \mathrm{~mm}$ steps (B). 2D maps of absorption and CD at $408 \mathrm{~nm}(\mathrm{C}$ and $\mathrm{E})$ and $284 \mathrm{~nm}(\mathrm{D}$ and $\mathrm{F})$.

homogeneous nature. A contrasting situation exists for the dropcoated film, where 7 out of 18 spectra showed large differences related to the supramolecular arrangement of the DPP chromophore (Fig. S22, ESI $\dagger$ ). The spectra are in the optimum absorption range, and therefore do not show differences arising from spectral distortion of the type noted above. Only one spot scanned in the drop coated film was similar to the largest CD measured with the MMP for the spin coated film (Fig. 4). Even so, the peak positions are slightly different, indicating that nonidentical supramolecular structure can be induced in both film preparations, and more diversity was observed in the drop coated film. It is important to note that when supramolecular differences are observed by CD and $g$-factor from MMP measurements, the absorption in the solid state might be not directly related to the sample thickness, as the hypochromic effect observed for the J-aggregate will be convoluted with the apparent chromophore concentration.

The CD imaging and CD from MMP mapping (with similar optimal absorption) are qualitatively similar for both the annealed spin- and drop- coated films, though the latter was much closer (Fig. 5). The CD spectral features from CDi measurements of the as-formed spin-coated film were about half the intensity in the $200-400 \mathrm{~nm}$ region but with opposite sign at $500 \mathrm{~nm}$ than that observed when annealed (Fig. 4).
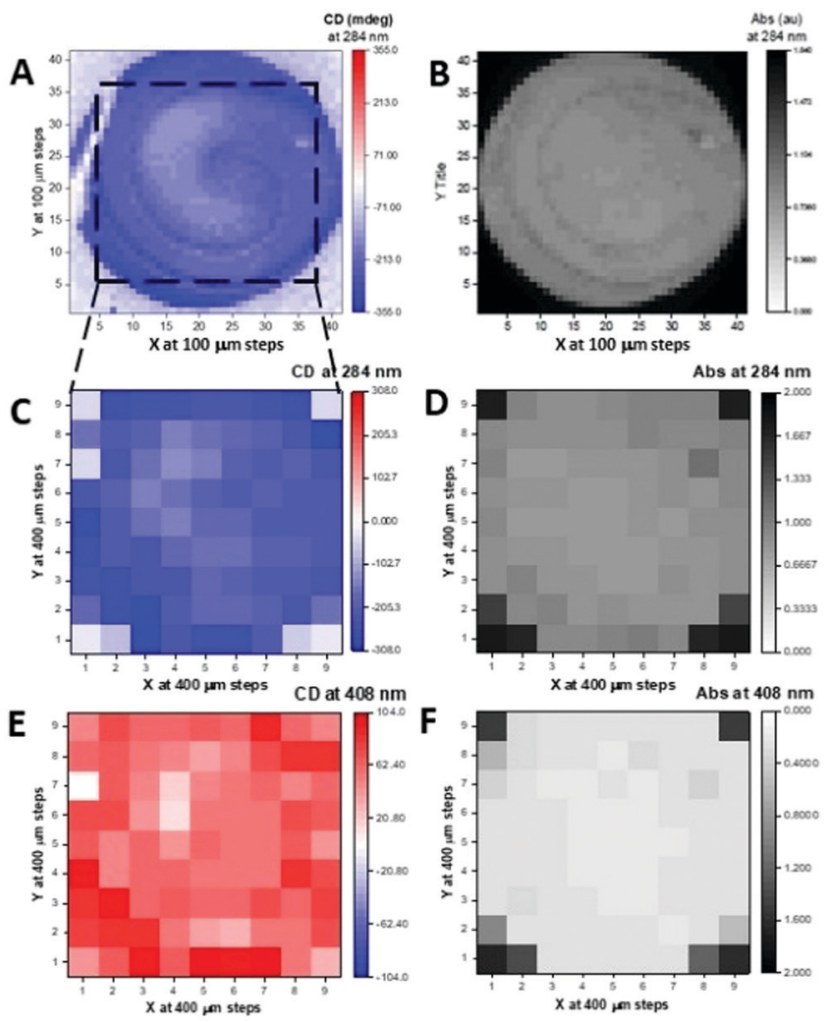

Fig. 3 Spin Coated Film 2D maps from MMP data. CD (A) and absorbance (B) $2 \mathrm{D}$ maps of $4 \times 4 \mathrm{~mm}$ area of $41 \times 41 \mathrm{grid}$ at $100 \mathrm{~m}$ steps scanned at fixed $284 \mathrm{~mm}$ wavelength. $C D$ (C) and Abs (D) 2D maps of the smaller dashed square area of $9 \times 9$ grid generated at $284 \mathrm{~mm}$ and at $408 \mathrm{~nm}$ for $C D(E)$ and $A b s(F)$ from 81 spectra.

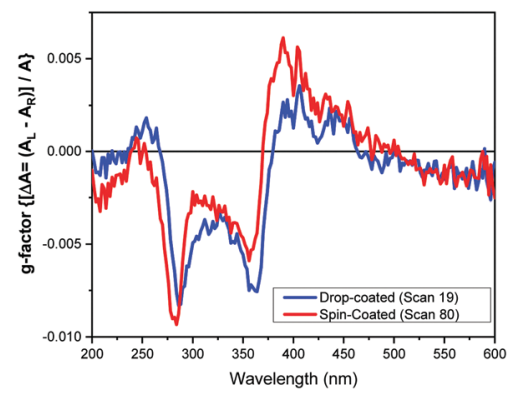

Fig. 4 Most similar $g$-factor spectra of 1 from a drop- and spin-coated films generated from the ratio between the spectra converted from mdeg to $\Delta A$ for the spectra (see Fig. S22 for all spectra, ESI $\dagger$ ).

Relatively large 2D maps scanned with the drop-coated thin film of 1 annealed at $120{ }^{\circ} \mathrm{C}$ for 30 minutes using B23 CD imaging and B23 Mueller Matrix Polarimetry $\left(\mathrm{MMP}_{i}\right)$ revealed areas of $\mathrm{CD}$ signal with opposite sign and variable intensity magnitude (Fig. 2). This feature was much less pronounced when observed with both absorption and optical microscopy demonstrating how the MMP mapping method can reveal more precisely the uniformity and chiroptical homogeneity of thin films. This study indicates unambiguously that areas in the films have different or variable supramolecular structures, 

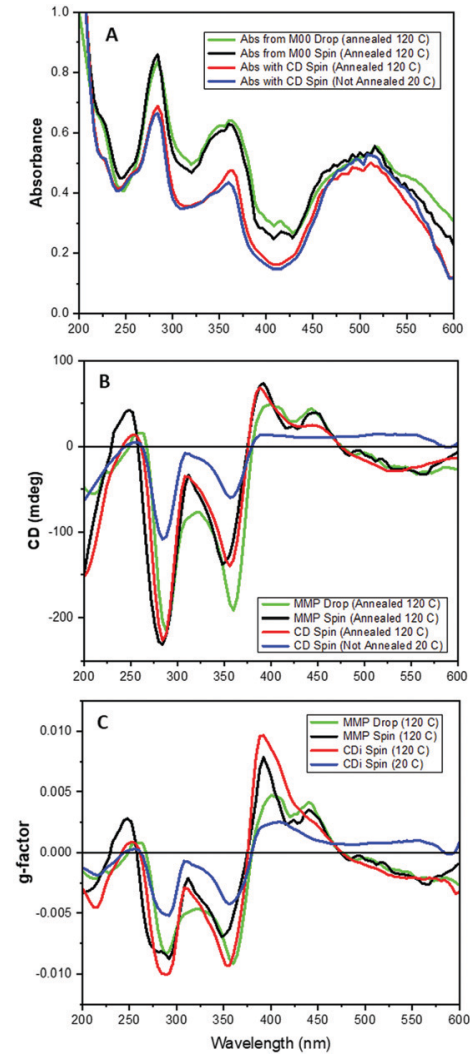

Fig. 5 Absorption (A), CD (B) and g-factor (C) spectra of 1 in annealed drop-coated film from MMP mapping (green) and spin coated from MMP (black), and from CDi of an as-formed film at $20^{\circ} \mathrm{C}$ (red) and annealed at $120{ }^{\circ} \mathrm{C}$ (blue).

indistinguishable using UV mapping or optical microscopy, that are detected using spatially-resolved CD from MMP data.

This study provides unique insight into the effect of deposition techniques and thermal annealing on the supramolecular structure of thin films of organic dyes, where other techniques would provide averaged signals that do not detect the inhomogeneities in the films. The MMP mapping using synchrotron light is thus a non-destructive and unique way to probe the supramolecular structure in thin films. The results discussed here can be viewed as proof of concept with the aim of incorporating these and similar structures into bulk heterojunctions and gain otherwise inaccessible details of structural domains in devices leading to a new understanding of the photovoltaic performance of chiral films and ability to control them. The relative arrangement of chromophores in a chiral sense will affect the material's photoinduced charge transport, and recent interest in these kinds of systems mean our findings and approach may be of use. ${ }^{35-37}$

We thank the University of Nottingham through the Propulsion Futures Beacon of Excellence and the EPSRC through the LDMI DTP. The Diamond Light Source Ltd (beamline B23) is thanked for providing beamtime (SM22017 and SM26044) and Drs T.-M. Gianga, T. Jávorfi and R. Hussain for beamline assistance.

\section{Conflicts of interest}

There are no conflicts to declare.

\section{References}

1 R. K. Gupta, R. Garai, M. Hossain, M. A. Afroz, D. Kalita and P. K. Iyer, J. Mater. Chem. C, 2021, 9, 8746.

2 Y. Diao, L. Shaw, Z. Bao and S. C. B. Mannsfield, Energy Environ. Sci., 2014, 7, 2145.

3 C. Cui and Y. Li, Aggregate, 2021, 2, e31.

4 R. B. Zerden, N. T. Shewmon, Y. Zhu, J. P. Mudrick, K. J. Chesney, J. Xue and R. K. Castellano, Adv. Funct. Mater., 2014, 24, 5993.

5 M. Stolte, S. Suraru, P. Diemer, T. He, C. Burschka, U. Zchieschang, H. Klauk and F. Würthner, Adv. Funct. Mater., 2016, 26, 7415.

6 J. R. Brandt, F. Salerno and M. J. Fuchter, Nat. Rev. Chem., 2017, 1, 0045.

7 C. Liu, Y. Li, M. V. Lee, A. Kumatani and K. Tsukagoshi, Phys. Chem. Chem. Phys., 2013, 15, 7917.

8 K. Fukumura, T. Hori, T. Masuda, D. Q. Duy, A. Fujii, Y. Shimizu and M. Ozaki, Jpn. J. Appl. Phys., 2013, 52, 05DB02.

9 S. E. Campbell, M. Collins, L. Xie and J. J. BelBruno, Surf. Interface Anal., 2009, 41, 347.

10 D. Zomerman, J. Kong, S. M. McAfee, G. C. Welch and T. L. Kelly, ACS Appl. Energy Mater., 2018, 1, 5663.

11 A. Namepetra, E. Kitching, A. F. Eftaiha, I. G. Hill and G. C. Welch, Phys. Chem. Chem. Phys., 2016, 18, 12476.

12 J. S. Moon, J. K. Lee, S. Cho, J. Byun and A. J. Heeger, Nano Lett., 2009, 9, 230. 13 D. Chi, S. Qu, Z. Wang and J. Wang, J. Mater. Chem. C, 2014, 2, 4383.

14 N. Berova, L. Di Bari and G. Pescitelli, Chem. Soc. Rev., 2007, 36, 914.

15 G. Pescitelli, L. Di Bari and N. Berova, Chem. Soc. Rev., 2014, 43, 5211.

16 G. Albano, M. Lissia, G. Pescitelli, L. A. Aronica and L. Di Bari, Mater. Chem. Front., 2017, 1, 2047.

17 C. Kulkarni, M. H. C. Van Son, D. Di Nuzzo, S. C. J. Meskers, A. R. A. Palmans and E. W. Meijer, Chem. Mater., 2019, 31, 6633.

18 G. Albano, L. A. Aronica, A. Minotto, F. Cacialli and L. Di Bari, Chem. Eur. J., 2020, 26, 16622.

19 J. Wade, J. N. Hilfiker, J. R. Brandt, L. Liirò-Peluso, L. Wan, X. Shi, F. Salerno, S. T. J. Ryan, S. Schöche, O. Arteaga, T. Jávorfi, G. Siligardi, C. Wang, D. B. Amabilino, P. H. Beton, A. J. Campbell and M. J. Fuchter, Nat. Commun., 2020, 11, 6137.

20 A. T. Rösch, Q. Zhu, J. Robben, F. Tassinari, S. C. J. Meskers, R. Naaman, A. R. A. Palmans and E. W. Meijer, Chem. - Eur. J., 2021, 27, 298.

21 G. Albano, G. Pescitelli and L. Di Bari, Chem. Rev., 2020, 120, 10145.

22 F. Zinna, C. Resta, M. Górecki, G. Pescitelli, L. Di Bari, T. Jávorfi, R. Hussain and G. Siligardi, Macromolecules, 2017, 50, 2054.

23 G. Albano, M. Górecki, G. Pescitelli, L. Di Bari, T. Jávorfi, R. Hussain and G. Siligardi, New J. Chem., 2019, 43, 14584.

24 R. Hussain, T. Jávorfi, C. S. Hughes, H. Sriram, R. Lashminarayanan and G. Siligardi, Symmetry, 2020, 12, 1847.

25 R. Hussain, T. Jávorfi and G. Siligardi, Front. Chem., 2021, 9, 61692B.

26 M. Grzybowski and D. T. Gryko, Adv. Opt. Mater., 2015, 3, 280.

27 D. Chandran and K. S. Lee, Macromol. Res., 2013, 21, 272.

28 Y. N. Li, P. Sonar, L. Murphy and W. Wong, Energy Environ. Sci., 2013, 6, 1684.

29 A. Ruiz-Carretero, N. R. Á. Rovelo, S. Militzer and P. J. Mésini, J. Mater. Chem. A, 2019, 7, 23451.

30 P. A. Hume, J. P. Monks, F. Pop, E. S. Davies, R. I. MacKenzie and D. B. Amabilino, Chem. - Eur. J., 2018, 24, 14461.

31 Z. Hao, A. Iqbal, N. Tebaldi and K. Praefcke, US. Pat., 5969154, 1999.

32 S. Stas, J. Y. Balandier, V. Lemaur, O. Fenwick, G. Tregnago, F. Quist, F. Cacialli, J. Cornil and Y. H. Geerts, Dyes Pigm., 2013, 97, 198.

33 F. Pop, J. Humphreys, J. Schwarz, L. Brown, A. van den Berg and D. B. Amabilino, New J. Chem., 2019, 43, 5783.

34 W. Kuhn, Trans. Faraday Soc., 1930, 26, 293.

35 T. Mikie, A. Saeki, Y. Yamazaki, N. Ikuma, K. Kokubo and S. Seki, ACS Appl. Mater. Interfaces, 2015, 7, 8915.

36 A. Seki, Y. Funatsu and M. Funahashi, Phys. Chem. Chem. Phys., $2017,19,16446$

37 S. Militzer, N. Nishimura, N. R. Ávila-Rovelo, W. Matsuda, D. Schwaller, P. J. Mésini, S. Seki and A. Ruiz-Carretero, Chem. - Eur. J., 2020, 26, 9998. 